\title{
Fault Surface Geometry: Examples from Offshore Niger Delta
}

\author{
Babangida Jibrin ${ }^{1}$, Yelwa N. A.,"* \\ ${ }^{1}$ Department of Geology and Mining, Ibrahim Badamasi Babangida University, Nigeria \\ ${ }^{2}$ Department of Geology, Usmanu Danfodiyo University, Nigeria \\ *Corresponding Author: nura.yelwa@udusok.edu.ng
}

Copyright (C) 2015 Horizon Research Publishing All rights reserved.

\begin{abstract}
Techniques for mapping the geometry of geological surfaces have been applied to faults mapped from 3D seismic data acquired offshore Niger Delta. The quality of the data was first improved by applying techniques that highlight faults based on the similarity of the seismic traces. Four faults were then tracked and surface models plotted using an algorithm that interpolates scattered data points at user-defined grid dimensions. The plots show that the faults exhibit a wide variety of geometries characterized by small-scale irregularities and more regular large-scale corrugations predominantly oriented along the dip direction. Although the surfaces were mapped in the time-domain, the consistent pattern of the long-wavelength corrugations suggests that the structures may not be entirely due to interpretation bias and velocity heterogeneity in Tertiary deltaic sediments. Results presented in this article highlight potential errors in subsurface structural models that assume simple and planar fault geometries.
\end{abstract}

Keywords Offshore, Niger Delta, 3D Seismic Data, Fault Traces, Fault Surface Geometry

\section{Introduction}

In the offshore Niger Delta, thrust faults result from up-dip gravitational failure and syn-sedimentary extension on the continental shelf where displacement is translated down-dip along detachment surfaces located within overpressured shales of the Akata Formation to deepwater. Faults are important in oil and gas exploration and production by restricting or allowing the flow of hydrocarbon fluids $[1,2]$. However, most faults are interpreted to represent simple and planar surfaces during routine structural interpretation workflows. In the Niger Delta, the cross sectional geometry of listric normal faults has been studied in substantial detail because of the significance and close links between the geometry of syn-sedimentary (growth) faults and hydrocarbon occurrence in hanging wall rollover anticlines [3]. Although several end-member models have been proposed to explain the cross sectional geometry of thrust faults in the deep-water Niger Delta [4], to date there has yet to be a documented study of the 3D geometry of the faults.

In recent years, considerable exploration efforts have focused on deepwater Niger Delta compressional structural domain with thrust related structures being the primary targets. As the search for new hydrocarbon reserves is intensified, the need for accurate detection and mapping of fault surface geometry for improved visualization and representation of faults in subsurface structural modelling will become more important. In recent years, advances in marine seismic acquisition and processing, along with the growing availability of good quality marine 3D seismic imaging of the West African continental margin, make the deepwater Niger Delta an ideal location for studying 3D fault geometry at sufficiently high resolutions.

In this article, techniques are described for highlighting the 3D geometry of fault planes mapped from a 3D se seismic data acquired over an area of overlapping maritime boundary between São Tomé and Príncipe referred to as the "Joint Development Zone" (Fig 1). The improved resolution of modern 3D seismic data, combined with advanced interpretation techniques for enhanced detection of faults allows us to map the geometry of fault surfaces with a good degree of certainty. We demonstrate that fault surfaces exhibit a wide variety of fault surface geometries most often over simplified. Results from this paper could have implications for subsurface structural models that assume simple and planar fault surface geometries. 


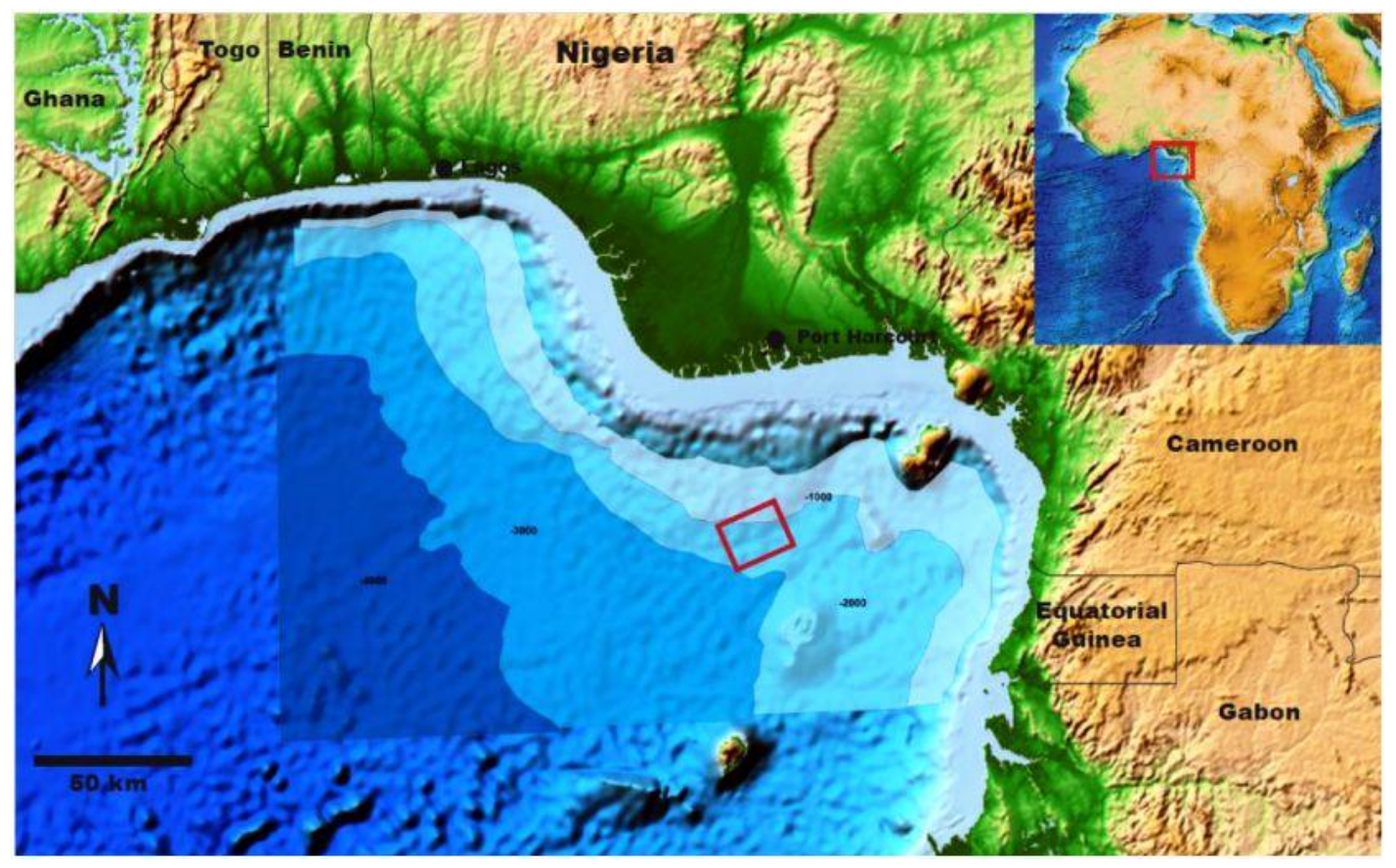

Figure 1: Bathymetric map of the Gulf of Guinea showing the location of the study area (red box)

\section{Materials and Methods}

\subsection{Data}

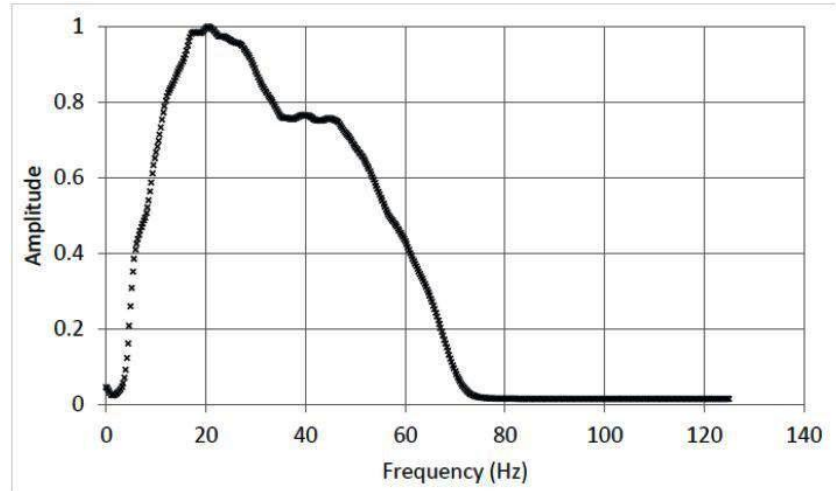

Figure 2. Frequency spectrum plot between 3.5 and $6.0 \mathrm{~s}$ two-way travel time.

The post-stack time-migrated 3D data have inline and crossline spacing of 25 and $12.5 \mathrm{~m}$ respectively. The recording interval is $9 \mathrm{~s}$ with a $4 \mathrm{~ms}$ sampling rate. The data are displayed with a reverse polarity and have been zero-phased migrated with vertical scale in seconds (s) two-way travel time. Spectral analysis (Fig 2) shows that the dominant frequency varies from 18 to $28 \mathrm{~Hz}$ between 3.5 and $6.0 \mathrm{~s}$ two-way travel time. A frequency of $\sim 20 \mathrm{~Hz}$ that appears to be the strongest in the amplitude spectrum plot was used to calculate the maximum vertical resolution of the data. The maximum vertical resolution is $\sim 25 \mathrm{~m}$ at shallower sections but deteriorates in the deeper sections. Vertical resolution was computed using an interval velocity versus depth plot from offshore Niger Delta [5]. The loss of seismic resolution is attributed to loss of frequency with depth in addition to fluid overpressures within marine shales of the Akata Formation [6]. The low resolution behind faults and the forelimbs is probably a result of rocks with contrasting velocities across faults and strain concentration in front of a propagating fault tip [7].

\subsection{Computing Multi-trace Similarity Data}

An attribute that detects and highlights the waveform similarity of adjacent trace pairs and the time difference between the traces interpreted as vectors was computed to highlight discontinuities and damage zones (Fig 3). A high similarity means the trace segments are similar in wave-shape and amplitude. Low similarity implies that the traces are dissimilar probably due to deformation. For improved detection of faults and visibility of fault zones, the attribute was computed trace to trace guided by the dips and azimuths of the traces. The similarity data are displayed in grey scale and normalized to between 0 and 1 . Darker shades (similarity values approaching 0) are interpreted as due to increasingly dissimilar traces and represents faults, discontinuities, and damage zones. Lighter shades (similarity values approaching 1) are due to increasingly similar traces. Comprehensive description of the mathematics of similarity computation applied to the data is described in $[8,9,10]$.

\subsection{Fault Surface Modeling}

Fault traces were manually tracked in vertical amplitude cross sections in the inline direction based on reflection terminations and or offsets. However, where reflector 
termination is poor due to reduced data quality, the traces were mapped in both vertical and horizontal (time-slice) cross sections using similarity attribute data based on discrete zones of low similarity that matches reflection offset at the location of the faults. The confidence of tracking the fault traces using similarity attribute is higher in Unit I, the poorly defined pattern of similarity in Unit II makes it difficult for any meaningful tracking of fault traces using the attribute. Traces of each of the faults were exported from Kingdom SMT seismic interpretation software in Landmark time format and loaded into a fault surface geometrical analysis project in SeisworksR2003 ASCII format in TrapTester structural modeling software. All fault surface calculations are performed in a "natural coordinate system". This is a set of xyz coordinates with an xy plane that is chosen to make the fault data points appear single value in $\mathrm{z}$. The $\mathrm{xy}$ plane is defined by first and second eigenvectors of the covariance matrix of the fault data points (This is a kind of a best-fit plane). All fault data points are transformed to the "natural coordinate plane" (ncp) with axes referred to as the "natural coordinate system" (ncs). However, the potentially irregular fault surface data points need to be resampled onto a grid using the multilevel b-spline method [11]. In terms of sampling, the basis function for b-spline is defined by the extent of the grid and all available data points such that the original data is honoured by the surface model. Sampling is performed at arbitrary xy locations. Essentially, this means that exactly the same surface model (incorporating all original data) is used at all sampling resolutions.

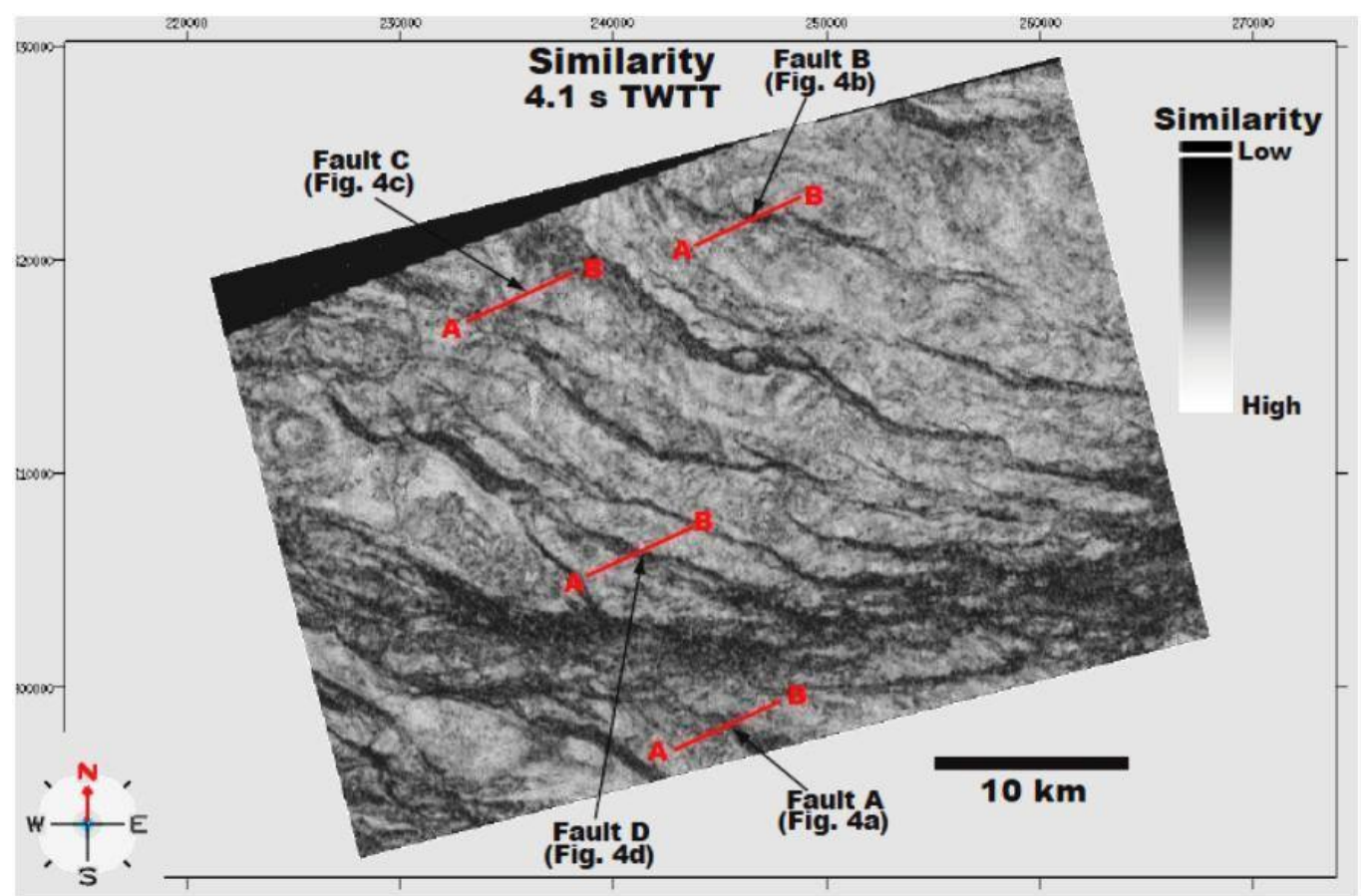

Figure 3. Similarity time slice showing the location of the seismic lines in Fig 4 (red lines).

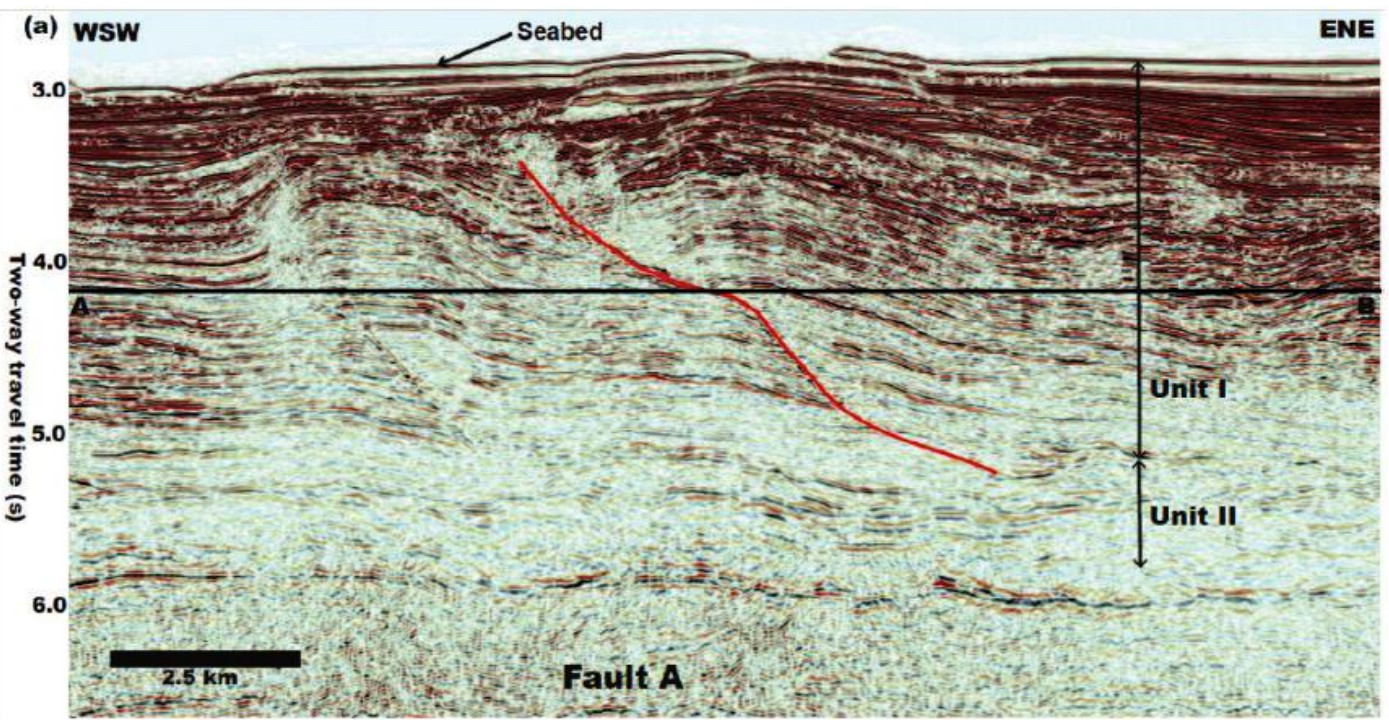



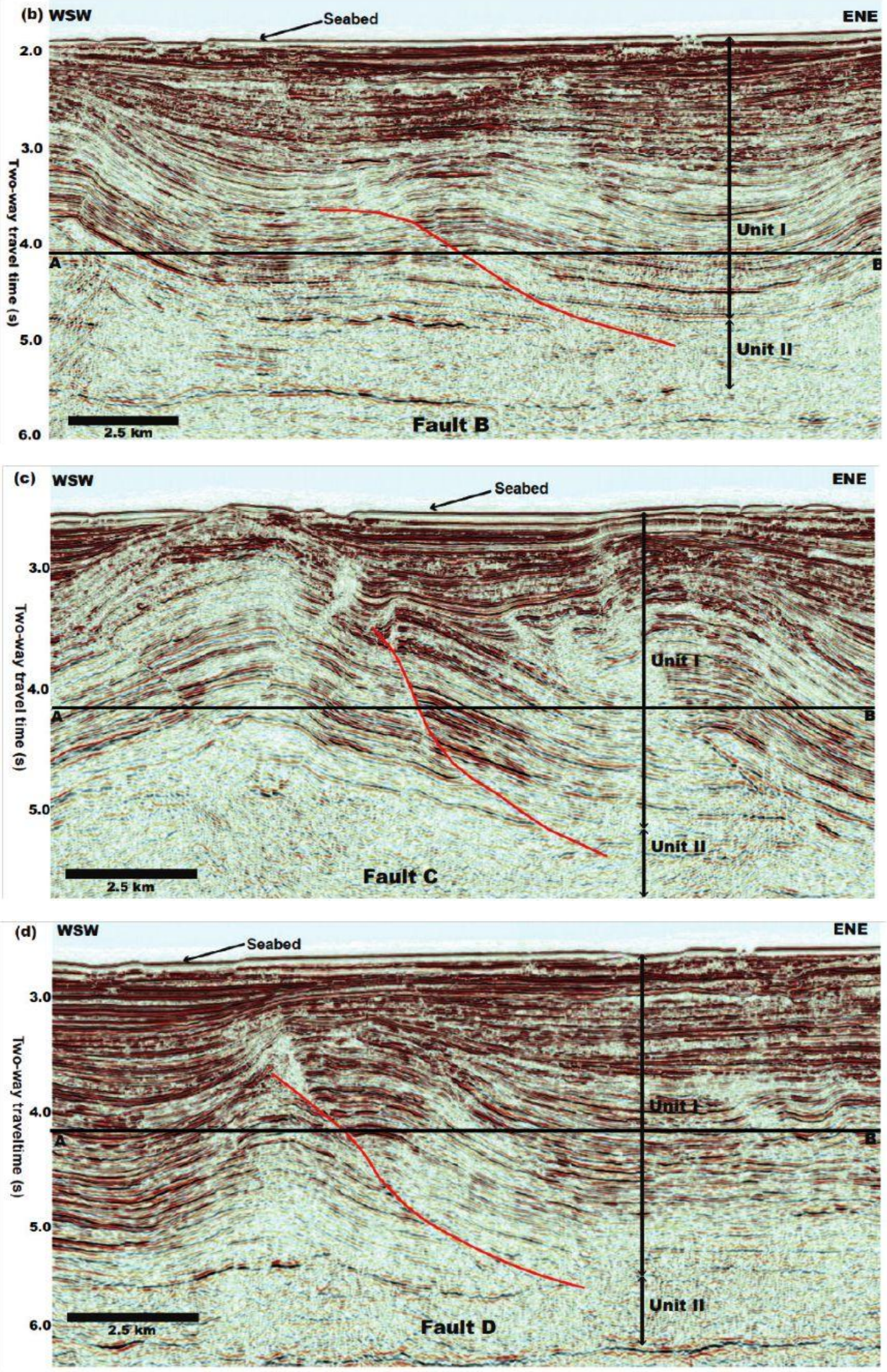

Figure 4. Seismic lines showing the vertical cross sectional geometry of faults A - D. The black horizontal line shows the location of the seismic amplitude and similarity time slice extracted at $4.1 \mathrm{~s} \mathrm{(Fig} \mathrm{3).} \mathrm{Vertical} \mathrm{scale} \mathrm{is} \mathrm{in} \mathrm{seconds} \mathrm{two-way} \mathrm{travel} \mathrm{time} \mathrm{and} \mathrm{horizontal} \mathrm{scale} \mathrm{is} \mathrm{in} \mathrm{kilometers.}$ 


\subsection{Data Analysis}

Models of geological surfaces calculated using scattered raw data are usually noisy, it is thus necessary that some smoothing is applied to the surfaces to reduce irregularities that may not be real structural features of the surfaces [11]. Most of the high frequency data contained in the gridded fault surfaces contributes to the small-scale undulations, while the low frequency data constitute the broader structures. In practical, short-wavelength features dominate the plots, but up-scaling the grid dimensions can reveal longer wavelength features [12]. The fault surfaces were modeled using a sampling grid size of $200 \mathrm{~m}$. This implies that topographic features with wavelengths of at least $200 \mathrm{~m}$ and four times the width of the individual fault traces (Inline spacing is $25 \mathrm{~m}$ ) can be visualized with minimal data sampling aliasing. The highest frequency contained in a gridded data set is referred to as "Nyquist frequency" and is the inverse of twice the grid size [13]. For a sampled surface to be truly representative of the original surface, the sampling frequency must be at least twice the diameter of the smallest surface undulation. Sampling resolution below the diameter can lead to an alias. All fault surface plots are displayed in strike views with horizontal scale in meters and vertical scale in seconds two-way travel time. However, an average velocity of $2000 \mathrm{~m} / \mathrm{s}$ obtained from a velocity profile of the Agbada Formation [5] was used to convert two-way travel time to depth.

\section{Results and Discussion}

The cross sectional geometries of the faults are presented in Fig 4. Faults in the area are discrete planar surfaces that sole into at least one or more detachment levels located near the top and middle of Unit II. The faults offset the deeper parts of Unit I into blocks of fairly uniform thickness. Displacement is reverse and predominantly within the unit, but in the shallower parts of the Unit I, well developed hanging wall folds progressively take up displacement. The faults have low dips with increased cross sectional curvature towards Unit III. Fault dips are typically between $10^{\circ}$ and $30^{\circ}$ and within the range for low angle reverse faults. Most of the faults die out near the base of Unit II but in places reach the seabed. Folds related to thrusting are geometrically similar to fault-bend and fault propagation folds.

3D plots of the fault surfaces (Fig 4) show a widespread occurrence of corrugations exhibited as semi-linear/linear narrow to broad grooves and ridges with lengths of up to $1500 \mathrm{~m}$ and widths ranging from $200 \mathrm{~m}$ and up to $1000 \mathrm{~m}$. Corrugation wavelengths are highly variable but range from $500 \mathrm{~m}$ and up to $2000 \mathrm{~m}$ (e.g. Fault A) and generally prominent in the upper parts of the surfaces but become narrower and eventually flattens as the faults sole into detachment surfaces (e.g. Fault B and Fault D). The corrugations are not perfectly cylindrical, but undergo abrupt down-dip change from a concave (depressions) to a convex geometry (culminations), or vice versa. These conical structures have widths of up to $800 \mathrm{~m}$ and are a common topographic feature of Faults A, Fault B and Fault D. Horizontal/cross corrugations are also commonly seen perpendicular to the main down-dip corrugation axes of some of the faults (blue arrows in Fault B and Fault D). These structures are typical vertical cross sectional features of thrust faults related to fault - bends in the Niger Delta compressional domain.

In normal faults, large-scale corrugations are speculated to form by the reactivation of pre-existing faults, folding of fault surfaces, and coalescence of fault segments to form through-going fault planes and the preservation and/or amplification of inherent random roughness in the direction of the most recent slip $[15,16]$. In addition, faults are also speculated to exhibit corrugations primarily due to the effects of host rock mechanical stratigraphy during slip and non-uniform tectonic deformation [17]. Until now, there has been little attempt to investigate the occurrence, scaling properties and origin of corrugations on thrust faults in the outer fold and thrust belt in the deep-water Niger Delta. In the deep-water Niger Delta, [18] demonstrated that most faults show evidences of relays and transfer zones. Soft-linked relays are known to develop by the gradational propagation of fault segments into an overlap position, while hard-linkage is via breached relays and connecting faults. Some of the faults connected by breached relays may be continuous; probably implying that geometric coherence is maintained by fault arrays. [19], demonstrated the preponderance of multiple displacement maxima on displacement - distance plots of thrust faults mapped from the Niger Delta compressional domain, implying that fault growth may be related to the progressive interaction of previously isolated fault arrays. The long-wavelength corrugations may have been formed by the coalescence of initially isolated segments to form thoroughgoing surfaces with the corrugations forming at points of segment linkage.

However, the key challenge is mapping and analyzing fault surface geometry in the time-domain. Subsurface velocity variation with depth due to heterogeneous lithology and fluid pressure distribution can impact on the real fault surface geometries. These are common phenomena in young, under compacted and over pressured sediments. Although structures imaged in TWT may experience geometric changes when depth converted due to lateral and vertical changes in seismic velocity associated with lithology, in the offshore Niger Delta, studies have shown that the most significant change in geometry occur occurs at the depth of the basement reflection and fault planes have similar geometries to their corresponding time sections [6]. Therefore, a key assumption in this study is that two-way travel time and depth are positively correlated. This assumption is based on the premise that lateral and horizontal velocity variation is minimal within the normally pressured interval that the faults are located (Unit II). 

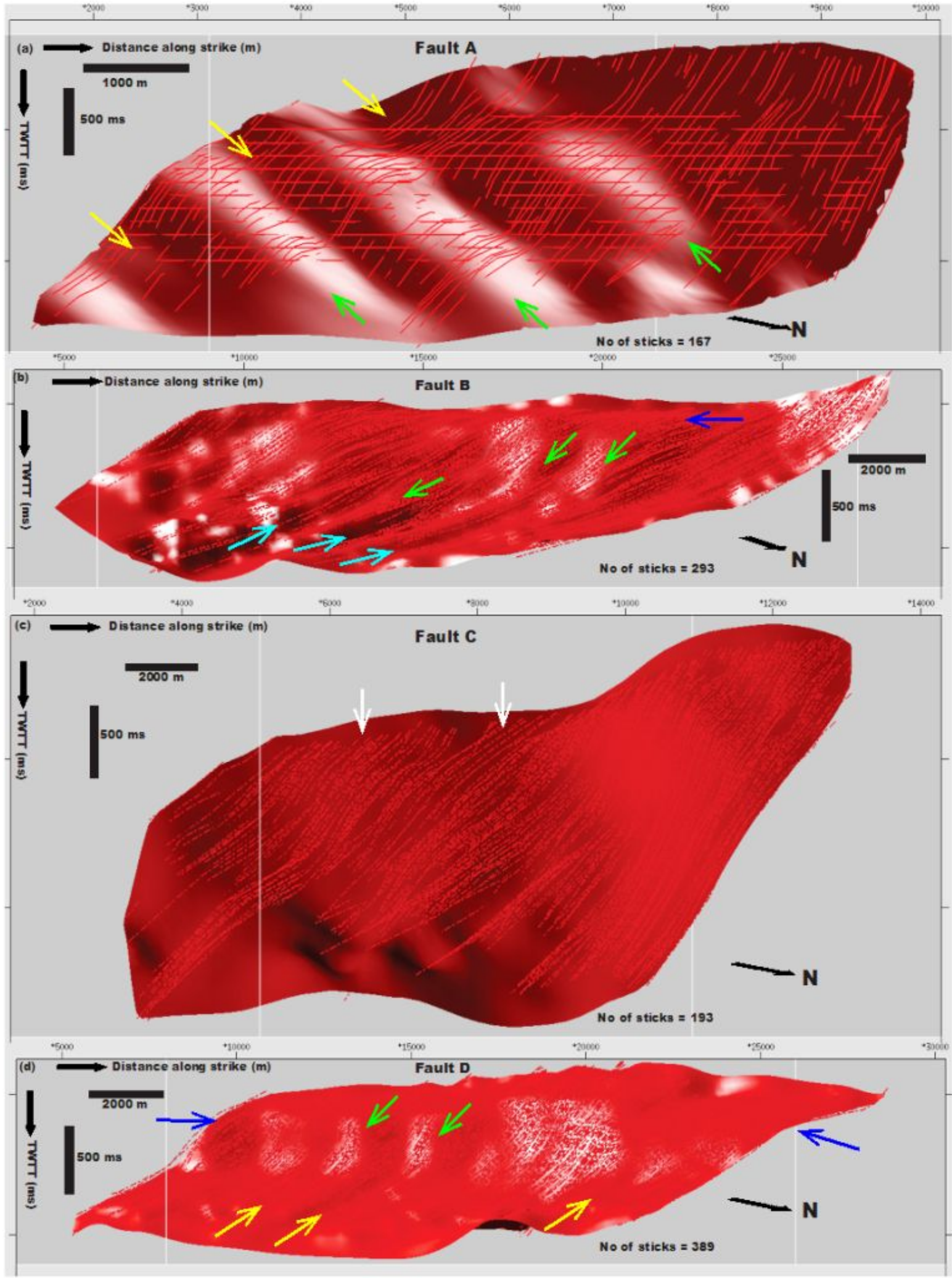

Figure 5. Strike views looking SW of illuminated surface models of Faults A - D. The red lines are the individual fault segments used in modeling the surfaces. The yellow and green arrows highlight corrugations (grooves and ridges respectively) in the fault dip direction. The blue arrows highlight corrugations in the strike direction, while the white arrows show planar geometries. Vertical scale is in milliseconds two-way travel time and horizontal scale is in meters. Vertical exaggeration is $\sim \mathrm{x} 1.6$. 


\section{Conclusions}

This article demonstrates that thrust faults exhibit a wide variety of geomorphic features visible at the scale of seismic resolution. However, additional work is required to rationalize the mechanisms responsible for the formation of corrugations in thrust faults that is presently poorly understood. Results presented in this article may have implications on the role of fault geometry in fluid leakage across faults, links between fault shape and wall rock deformation and subsurface structural models that assume planar fault surface geometry.

\section{Acknowledgements}

The authors are grateful to Petroleum Geo-Services (PGS) for providing the $3 \mathrm{D}$ seismic data. Seismic Micro-Technology (SMT) and dGB Earth Sciences are thanked for donating Kingdom and Opendtect software programs respectively. We are grateful to Badleys Geoscience for providing the TrapTester used in plotting the $3 \mathrm{D}$ grids of the fault surfaces.

\section{REFERENCES}

[1] Knipe, R.J., G. Jones, and Q.J. Fisher, Faulting, fault seal and fluid flow in hydrocarbon reservoirs: an introduction, in Jones, G., Knipe, R.J. and Fisher, Q.J. (Ed), Faulting, Fault Sealing and Fluid Flow in Hydrocarbon Reservoirs (Geological Society of London, Special Publications, 1998) 147, vii-xxi.

[2] Sorkhabi, R. and Y. Tsuji, 2005, The place of faults in petroleum traps, in Sorkhabi, R. and Tsuji, Y. (Ed), Faults, Fluid Flow, \& Petroleum Traps (American Association of Petroleum Geologists Memoir, 2005) 85, 1-31.

[3] Doust, H., and E. Omatsola, 1990, Niger Delta divergent/passive margin basins, in J.D. Edwards and P.A. Santogrossi, (Ed), (American Association of Petroleum Geologists memoir, 1990) 48, $201-238$.

[4] Corredor, F., J.H. Shaw, and F. Bilotti, Structural styles in the deep-water fold and thrust belts of the Niger Delta, American Association of Petroleum Geologists Bulletin, 89, 2005, 753-780.
[5] Cobbold, P.R., C.J. Benjamin, and L. Helge, Structural consequences of fluid overpressure and seepage forces in the outer thrust belt of the Niger Delta, Petroleum Geoscience, 15, 2009, 3-15.

[6] Maloney, P.D., Seismic analysis of the Niger Delta gravitational detachment systems, doctoral diss., Durham University, 2011.

[7] Erslev, E. A., Trishear fault-propagation folding, Geology, 19, 1991, 617-620.

[8] Tingdahl, K.M., Improving seismic chimney detection using directional attributes, Developments in Petroleum Science, 51, 2003, 157-173.

[9] Tingdahl, K.M., and P. de Groot, Post-stack dip and azimuth processing, Journal of Seismic Exploration, 12, 2003, 113-116.

[10] Tingdahl, K.M and M. de Rooij, Semi-automatic detection of faults in 3-D seismic data, Geophysical prospecting, 53, 2005, 533-542.

[11] Lee, S., G. Wolberg, and S.Y. Shin, Scattered data interpolation with multilevel b-splines, IEEE transactions on visualization and computer graphics, 2, 1997, 228-244.

[12] Stewart, S.A., and R. Podolski, Curvature analysis of gridded geological surfaces, in M.P. Coward, T.S. Dalbatan, \& H. Johnson (Ed), Structural Geology in Reservoir Characterization (Geological Society, London, Special Publications, 1998) 127, 133-147.

[13] Wynn, T.J., and S.A. Stewart, The role of spectral curvature mapping in characterizing subsurface strain distributions, Geological Society, Special Publications 1, 2003, 127-143.

[14] Nyquist, H., Thermal agitation of electrical charges in conductors, 1928.

[15] Ferrill, D.A., J.A. Stamatakos, and D. Simms, Normal fault corrugation: implications for growth and seismicity of active normal faults, Journal of Structural. Geology, 21, 1999, 1027-1038.

[16] Sagy, A., and E.E. Brodsky, Geometric and rheological asperities in an exposed fault zone, Journal of Geophysical Research, 114, 2009, 1-15.

[17] Martel, S.J., Mechanical controls on fault geometry, Journal of Structural Geology, 21, 1999, 585-596.

[18] Bergen, K.J., and J.H. Shaw, Displacement profiles and displacement-length scaling relationships of thrust faults constrained by seismic reflection data, The Geological Society of America Bulletin, 122, 2010, 1209-1219. 